\title{
Eating Habits, Family Flexibility and the Body Mass Index (BMI) in Gifted Students
}

\author{
Asghar Pouresmali1 ${ }^{1}$ Parastoo Semsarilar², Mehri Mowlaie1, Jaber Alizadeh Goradel ${ }^{3}$ \\ ${ }^{1}$ Department of Psychology, Mohaghegh Ardabili University, Ardabil, Iran \\ ${ }^{2}$ Department of Psychology, University of Tabriz, Tabriz, Iran \\ ${ }^{3}$ Young Researchers and Elite Club, Ardabil Branch, Islamic Azad University, Ardabil, Iran \\ Email: asgharpouresmali@uma.ac.ir
}

Received 27 June 2015; accepted 5 October 2015; published 9 October 2015

Copyright (C) 2015 by authors and Scientific Research Publishing Inc.

This work is licensed under the Creative Commons Attribution International License (CC BY).

http://creativecommons.org/licenses/by/4.0/

(c) (i) Open Access

\begin{abstract}
The aim of this research was to examine the effect of eating habits and family flexibility on the body mass index in gifted students of the eighth and ninth grade of high school. The research design of this study was descriptive-correlation. The statistical population of this research included all high school gifted students of the eighth and ninth grade. The sample consisted of 220 gifted students who were selected by random sampling method. The average age of these participants was 14.56 years old, SD 10.41. Average participants BMI was 31.25, SD 3.12. One hundred and fifteen $(52.28 \%)$ of these students were females and one hundred and five $(47.72 \%)$ were males. Family flexibility was measured by Shakeri flexibility scale, eating habits were measured through Coker and Roger Eating Habits Questionnaire and body mass index was tested by Omron digital device. Using SPSS software, the data were analyzed to calculate correlation and simultaneous regression. The results of correlation showed that in these students, concern with weight and dieting and total eating habits have significant relationship with BMI $(P<0.001)$. The result of simultaneous regression also showed that concern with weight and dieting and total eating habits could explain BMI in these students $(P<0.001)$ and family flexibility could not explain BMI in these students $(P<$ 0.005). The results emphasize the more important role of eating habits than family flexibility on BMI in gifted students because of sensitive and higher level of intelligence and high peer competitions.
\end{abstract}

\section{Keywords}

Eating Habits, Family Flexibility, Body Mass Index (BMI), Gifted Student

\section{Introduction}

Increasing growth of obesity in the world was restricted to adults until a few years ago but over the past two

How to cite this paper: Pouresmali, A., Semsarilar, P., Mowlaie, M. and Goradel, J.A. (2015) Eating Habits, Family Flexibility and the Body Mass Index (BMI) in Gifted Students. Open Journal of Medical Psychology, 4, 116-123.

http://dx.doi.org/10.4236/ojmp.2015.44012 
decades children and adolescents have also been involved [1]. Obesity is a risk factor for non-communicable diseases such as diabetes, cardiovascular disease, hypertension, stroke and cancer [2]-[5]. For this reason, to evaluate the fitness of an individual, an indicator is defined at the international level, BMI is an accepted indicator for those who are white Caucasian like Europeans, Americans and Iranians [6]. This has been known as the best method for calculating weight at the center for the prevention of diseases in the United States since 2000 [7]. This index is accepted as the standard based on extensive studies and calculates weight for height and is obtained by dividing weight in kilograms by square of height in meters. Accordingly, BMI less than 18.5 indicates underweight, between 18.5 and 24.9 is average, between 25 and 30 is overweight and above the $30 \mathrm{~kg} / \mathrm{m}^{2}$ is considered obesity [8]. In addition, obesity has also been effective on psychological factors such as self-esteem and body perception, mental health, and emotion regulation [9] [10]. Adolescent weight gain is a result of interaction between genetic and environmental factors [9]. On the other hand, the psychological and social factors, including personality type, anxiety level, family environment, have been observed to have a significant relationship with obesity [11]. Also, as proper eating and health habits of adolescents are formed in the context of home, home environment can have lasting effects on the adolescent weight [12]. The study of family as the major social institution and the first system affecting growth and development of children and adolescents, has long been discussed by researchers. Olson is one of those who have examined the family in a systemic view [13]. Dimensions addressed in Olson's model include three dimensions: 1) family cohesion, 2) family flexibility, 3) family relationship. Cohesion as one of the most influential family structures is a sense of connection and emotional commitment of the members of the family to each other (Olson, 1999). Lingren (2003) defines cohesion as a sense of emotional closeness with others; he believes two qualities of the cohesion of the family include the commitment and spending time together [14]. Commitment means the desire to spend time and energy in family activities and prevent the negative impact of factors such as employment issues. According to Lingren (2003), another dimension of cohesion is to spend time together among family members. Strong families in this area frequently plan programs and times for group activities. The second dimension of Olson's hybrid model is flexibility and is defined as follows: changes in roles, rules, control and discipline of the family [13].

Zimmer-Gembeck and Lockes [15] stated that as the family relationship was more positive, the rate of using avoidant coping strategies in teenagers was reduced. Damas and Laughlin (2001) concluded that the children of families with cohesion and flexibility had high problem solving ability and social competence [16]. Victor, Bernat \& Bernstien (2007) found that family flexibility was negatively correlated with anxiety and stress. Family cohesion and flexibility are two dimensions of Olson's combined circular model of family [17]. In flexible families, leadership and management of the family are democratic and less authoritarian and younger family members also participate in decision-making. From the perspective of family factors, family as the first transferor of social values plays an important role in the spread of eating disorders. Several theorists have attempted to examine the role of family to identify the specific pattern of family functioning in creating these disorders [18] [19]. The review of different researchers' view in this area has found researches emphasizing on the relative influence of mothers, fathers, grandparents, general feedback of parents, family flexibility, parenting styles in the development of eating disorders in children [9] [10]. Despite the results of the research findings of other studies have been inconsistent with the above findings on the impact of flexibility on obesity [12].

In addition to the impact of psychological stressors and familial factors in the development of eating disorders, eating habits are other variables playing a decisive role in the development of bulimia nervosa and loss of appetite, which consists of worry, overeating, and inhibition [20]. From a cognitive point of view, anxiety is referred to as a chain of mental thoughts and images having negative and somewhat uncontrollable emotional charge and is concerned with individual efforts to solve a problem whose outcomes are vague and is likely to have a loss. Some psychologists believe that anxiety is an avoidance emotional response resulting in a decrease in emotional distress, control gain and prevention of more intense negative emotions in short-term [21]. According to researches, anxiety plays a role in both mental disorders [22] [23] and physical health status [24] [25]. Another component of eating habits is inhibition, so that there is a conflict that because of the prohibition of forbidden foods, obese people tend to eat more of these foods. This eating style is called inhibition. Inhibition style cannot predict overeating in emotional and stressful conditions [26]. Behavioral and physiological data indicate that the style only indicates the vulnerability of the individual to regain weight [27]. However, in another research studying twins and their families, researchers found that inhibition style can be a predictor of weight gain in the long term [28]. The last component of eating habits is overeating, which is defined as the consumption of large amounts of food in a short duration (e.g. less than two hours), when the person subjectively experience loss of 
control [18]. The study of Rahimian Boogar, Nouri, Oreizy, Molavi, Foroughi Mobarake (2007) showed that overeating style with high scores was positively correlated with obesity and body mass index [29]. However, the study by Billings and Moos (2008) showed that overeating style was not associated with increasing consumption of fats and carbohydrates and got a lot of energy [19]. Since the study population will consist of gifted students, the generation will have the responsibility for the country's future, a major objective of the educational system is fostering students who are able to actualize their potential capacities and play an effective role in society. Gifted students are naturally endowed with a high degree of general mental ability or extraordinary ability in a specific sphere of activity or knowledge. The designation of giftedness is largely a matter of administrative convenience. In most countries the prevailing definition is an intelligence quotient (IQ) of 130 or above. It is estimated that students who are gifted and highly talented encompass $5 \%$ to $15 \%$ of the school age population. These advances students can have increased capabilities in academics, creativity, music, dance, art, and/or leadership [30].

Meanwhile, gifted students are of especial importance since it is predicted that they take responsibility at high-level management positions in the future thus factors that can play role in their psychological status should be identified and strengthened if in the positive direction or attempted to treat or eliminate them if in the negative direction. Therefore, with regard to what has been said and contradictions in previous studies and the lack of internal investigations, this study aims at examining the role of the family's eating habits and flexibility on body mass index of gifted students.

\section{Method}

The participant's eating habits was performed by Eating Habits Questionnaire [31], in order to measure the family flexibility, Shakeri's Family Flexibility Questionnaire [32] was used and finally the participant's BMI was tested through Omron digital device. The population of this study includes all boys and girls gifted students of eight and ninth grade of high school in 2014-2015. Among them, two-hundred and twenty students were selected according to Morgan table as sample groups by simple random method. All of the participants consented to take part in this study.

\section{Materials}

\subsection{The Eating Habits Questionnaire}

The Eating Habits Questionnaire (EHQ; Coker \& Roger, 1990), a self-report questionnaire assessing a range of existing and potential eating disorders, was also given. The scale consists of 57 true/false items, comprising three major factors: 1) concern with weight and dieting, 2) restrained eating, and 3) overeating. In a sample of undergraduate females, it had an internal consistency of 0.91 and test-retest reliability of 0.95 (Coker \& Roger, 1990). The EHQ also has good concurrent validity (0.87) with the Bulimic Investigatory Test, Edinburgh (BITE; Henderson \& Freeman, 1987) and the Eating Attitudes Tests (Garner \& Garfinkel, 1979). Furthermore, it has good predictive validity with a student population, distinguishing between diagnosed eating disordered patients and normal participants (Coker \& Roger, 1990). The items were keyed according to the valence of the loading. In items with a negative loading, a "false" response was awarded a point and a "true" response was given a zero. For positively loaded items, a "true" response was awarded a point. The three subscales and the total score were obtained by summing individual items.

\subsection{Shakeri's Family Flexibility Questionnaire}

Shakeri's Family Flexibility Questionnaire [32] was adapted based on Olson's (1999) integrated model. It includes 16 items each measured by Likert scale (strongly agree, agree, no opinion, disagree, strongly disagree). The maximum score possible in this test is 80 and the minimum score is 16 . The reliability and the validity of the instrument were confirmed by Shakeri in a study on 48 participants. The internal reliability of the questionnaire by Cronbach's alpha was reported as equal to 0.89 . The results of factor analysis indicated that the questionnaire contains only a general factor (g) called flexibility.

\subsection{Body Mass Index}

Body Mass Index was measured using Omron digital device made in Japan with an accuracy of $0.1 \%$ for mea- 
suring weight in $\mathrm{kg}$ and body mass index (BMI).

\section{Results}

Table 1 shows Descriptive statistics of gifted students in age and sex.

Table 2 shows Descriptive statistics of eating habits and their subscales, family flexibility and BMI in gifted students. BMI has 21.55 mean with 3.82 SD, total eating habits has 21.24 mean with $7.90 \mathrm{SD}$, and subscales of total eating habits include concern with 10.68 mean and 3.91 SD, restrained eating with 4.56 mean and 2.28 SD, and overeating with 21.24 mean and 7.90 SD. Finally family flexibility has 54.38 mean and 8.65 SD.

Table 3 shows correlation between Body mass index with family flexibility, eating habits and its subscales. The data show that of these variables, total eating habits and concern have significant correlation with body mass index in gifted students $(P<0.01)$.

The results of simultaneous regression in Table 4 indicate that there are multiple correlation $(r=0.363)$ and total eating habits predict $13 \%$ variance of body mass index (criterion variable), this amount with $(\mathrm{F}=16.53)$ and $(P<0.001)$ is significant.

Subsequently the results of simultaneous regression indicate that of subscales of eating habits, only concern could predict BMI in gifted students $(P<0.001)$.

Finally as seen in Table 5, family flexibility in gifted students has multiple correlation $(r=0.093)$ and can predict 0.009 variance of BMI that this amount is this amount with $(\mathrm{F}=0.956)$ and $(P<0.05)$ is not significant.

Table 1. Demographical characteristics of participants.

\begin{tabular}{|c|c|c|c|c|c|}
\hline \multirow{2}{*}{\multicolumn{2}{|c|}{ Variables }} & \multicolumn{2}{|c|}{ Girls } & \multicolumn{2}{|c|}{ Boys } \\
\hline & & Frequency & Percent & Frequency & Percent \\
\hline \multicolumn{2}{|c|}{ Gender } & 115 & 52.27 & 105 & 47.72 \\
\hline \multirow{3}{*}{ Age } & 14 & 54 & 46.95 & 48 & 45.71 \\
\hline & 15 & 50 & 43.47 & 52 & 49.53 \\
\hline & 16 & 11 & 9.58 & 5 & 4.76 \\
\hline \multirow{2}{*}{ Grade } & 8th & 60 & 52.17 & 55 & 52.38 \\
\hline & 9th & 55 & 47.83 & 50 & 47.62 \\
\hline
\end{tabular}

Table 2. Descriptive statistics of eating habits and their subscales, family flexibility and BMI in gifted students.

\begin{tabular}{cccc}
\hline Variables & Frequency & Mean & Standard deviation \\
\hline Body mass index & 220 & 21.55 & 3.82 \\
Concern & 220 & 10.68 & 3.91 \\
Restrained eating & 220 & 4.56 & 2.28 \\
Overeating & 220 & 6.01 & 1.19 \\
Total eating habits & 220 & 21.24 & 7.90 \\
Family flexibility & 220 & 54.38 & 8.65 \\
\hline
\end{tabular}

Table 3. Correlation coefficients between eating habits and their subscales, family flexibility and BMI in gifted students.

\begin{tabular}{ccccccc}
\hline Variables & Body mass index & Concern & Overeating & Restrained eating & Total eating habits & Family flexibility \\
\hline Body mass index & 1 & & & & & \\
Concern & $0.31^{* *}$ & 1 & & & & \\
Overeating & 0.03 & -0.11 & 1 & & & \\
Restrained eating & 0.08 & $0.32^{* *}$ & -0.13 & 1 & 1 \\
Total eating habits & $0.36^{* *}$ & $0.82^{* *}$ & 0.08 & $0.59^{* *}$ & $-0.30^{* *}$ & 1 \\
Family flexibility & -0.09 & -0.11 & -0.001 & $-0.44^{* *}$ & \\
\hline
\end{tabular}

** $P<0.001, * P<0.005$. 
Table 4. The result of simultaneous regression of body mass index by total eating habits and their subcomponents factors in gifted students.

\begin{tabular}{|c|c|c|c|c|c|c|c|}
\hline & $\mathbf{R}$ & R Squared & Adjusted R square & Std. Error of Estimates & $\mathbf{F}$ & Beta & Sig \\
\hline Total eating habits & 0.363 & 0.132 & 0.124 & 3.581 & 16.530 & 0.363 & 0.001 \\
\hline Subscales & B & SEB & Beta & $\mathrm{t}$ & sig & & \\
\hline Concern & 0.309 & 0.093 & 0.319 & 3.316 & 0.001 & & \\
\hline Restrained eating & -0.013 & 0.161 & -0.008 & -0.083 & 0.934 & & \\
\hline Overeating & -0.008 & 0.287 & -0.002 & -0.026 & 0.979 & & \\
\hline
\end{tabular}

Table 5. The result of simultaneous regression of body mass index by family flexibility in gifted students.

\begin{tabular}{cccccccc}
\hline Model & R & R Squared & Adjusted R square & Std. Error of Estimates & F & Beta & Sig \\
\hline Family flexibility & 0.093 & 0.009 & 0.001 & 3.826 & 0.956 & -0.093 & 0.330 \\
\hline
\end{tabular}

\section{Discussion}

The aim of the present study was to examine the role of eating habits and family flexibility on body mass index in gifted students. The results of simultaneous regression showed that of sub-components of eating habits include concern, inhibition and overeating in gifted students, only inhibition variable could significantly predict BMI in these students. The results of simultaneous regression also showed that total eating habits in these students had significant role in predicting BMI. This findings is consistent with previous researches [9] [21] [25] and inconsistent with [33].

For explanation of the findings it can be said that the label of being gifted in addition to the individual, several expectations and demands are created from the environment for individuals. These expectations are based on several assumptions, plans and objectives of relatives (parents and teachers) and living environment for gifted people, this can in some cases lead to the imposition of ideas, opinions and programs of others to gifted people. According to the competitive atmosphere and existing intelligent counterparts in schools of gifted students, when a student goes to these schools he or she has to accept specific programs of lives and schedules of these schools. According to current-cultural patterns among adolescents, body weight is considered as an indicator of fitness and beauty. Lots of images of skinny models in media, widespread expression of negative thoughts about obesity, advertising variety of diets as a control weight method encourage paying attention to weight and being thin and this acceptance is possibly not pleasant to a number of gifted people and affects them with rumination and concern about eating habits. Another explanation in the area is the stress, students experience in their social academic and their own family life. It is believed that in addition to the label of being gifted that brings stress, adolescence and developmental changes in this period along with the separation from normal students and denial of equal opportunities for growth and extremely high expectations of the family are enough for these people to be stressful.

Gifted students have higher levels of intelligence, work to pay more attention to their mental functioning and therefore enjoy a higher self-awareness criterion than that of normal students. In other words, possibly higher intelligence leads to higher awareness of these individuals from their states of mind and thus more concern about eating habits that are associated with physical appearance. It can be said that anxiety is a response to stressful life events and in recent decades it has been addressed in the context of anxiety disorders [22] [23]. Grosec's findings (2001) showed that gifted students had higher academic ability but it seemed that the academic ability of these students was not sufficient to reduce stress and anxiety, because many students with high academic potential were suffering from psychological agitation and social incompatibility [34]. These people from the early years of primary school perceive themselves as a different person and this perception leads to a negative selfimage [35]. On the other hand, Terman (1925) showed that gifted individuals in all areas such as intelligence, physical condition, social acceptance, academic achievement, emotional stability and ethical issues were superior and value the norms of society and care for the rights and the needs of the community members [36]. It is also said that these people are flamboyant and stubborn, are not understood by others and hence are withdrawn, all these problems can be associated with concerns about body mass index [37].

The results of regression analysis showed that family flexibility in gifted students was not a significant pre- 
dictor of BMI. These results are consistent with findings of [38] and inconsistent with the findings of [39] [40].

Low family flexibility unlike Western individualist societies, in collectivist cultures has brought positive consequences. Thus, social environment and cultural context of the society play a crucial role in the dual impact (positive and negative) of flexibility on people [41]. Since the cultural context of Iran is almost a collectivist context, it is expected that low flexibility can play a positive role in adolescent BMI but the present study finds no relationship between family flexibility and BMI of adolescents, and this result confirms the results of researchers that show the flexibility of family especially in traditional and collective cultures has not fixed findings [42].

The present findings can also be explained by considering the students' age and adolescence because many studies have confirmed that factors outside the family, especially peer group, are more effective on teenagers and when teens spend less time with family members, peers become increasingly important. Intimate friendship provides opportunities to explore themselves and develop a deep understanding of others, through open and honest communication teenage friends become sensitive about the strengths, weaknesses, needs and desires of each other and the process helps self-concept and to perceive others [43]. Thus, diminishing the influence of family flexibility like fading the influence of other features of parents on adolescent behaviors and functions including their BMI is not illogical and unexpected, and it seems that psychological and environmental behaviors and characteristics that could affect adolescent BMI are more influenced by their friends and peers rather than family functions, that more researches in this area are recommended to confirm whether family functions are important in adolescent BMI or not.

\subsection{Limitation}

The subjects of this study are from the student population that cannot be generalized to other groups. Also, this study is done at the adolescence age that is not valid to be generalized to other age groups and other sections of school.

\subsection{Suggestion}

It is suggested to carry out the research at different grades of school and non-school groups and also non-adolescent age groups, and evaluate other variables such as mentally retarded individuals. In the field of applied suggestions it can be said that through consultants and trainers of schools of gifted students, consultations will be held for students to evaluate possible causes of these anxieties and stresses. On the other hand, it is recommended that parents and schools of gifted students provide students with the freedom of choice to delegate responsibility and set goals.

\section{References}

[1] Konttinen, H., Haukkala, A., Hteenkorva, S., Silventoinen, K. and Jousilahti, P. (2009) Eating Styles, Self-Control and Obesity Indicators. The Moderating Role of Obesity Status and Dieting History on Restrained Eating. Appetite, 53, 131-134. http://dx.doi.org/10.1016/j.appet.2009.05.001

[2] Ning, F., Pang, Z.C., Laatikainen, T., Gao, W.G., Wang, S.J., Zhang, L., Tuomilehto, J. and Qiao, Q. (2013) Joint Effect of Family History of Diabetes with Obesity on Prevalence of Type 2 Diabetes Mellitus among Chinese and Finnish Men and Women. Canadian Journal of Diabetes, 37, 65-71. http://dx.doi.org/10.1016/j.jcjd.2012.12.001

[3] Schutter, A., Lavie, C. and Milani, R. (2014) The Impact of Obesity on Risk Factors and Prevalence and Prognosis of Coronary Heart Disease-The Obesity Paradox. Progress in Cardiovascular Diseases, 56, 401-408.

[4] Dong, B., Ma, J., Wang, H. and Wang, Z. (2013) The Association of Overweight and Obesity with Blood Pressure among Chinese Children and Adolescents. Biomedical and Environmental Sciences, 26, 437-444.

[5] Sugama, C.H., Isa, K., Okumura, K., Iseki, K., Kinjo, K. and Ohya, Y. (2013) Trends in the Incidence of Stroke and Cardiovascular Risk Factors on the Isolated Island of Okinawa: The Miyakojima Study. Journal of Stroke and Cerebrovascular Diseases, 22, e118-e123. http://dx.doi.org/10.1016/j.jstrokecerebrovasdis.2012.08.016

[6] Parsay, S. (2008) Overweight in Iran: The Right Diet to Prevent Obesity in Children. http://www.aappublications.org/content/123/2/697full

[7] Belue, R., Francis, L.A. and Colaco, B. (2008) Mental Health Problems and Obesity in a Nationally Representative Sample of Adolescents: Effects of Race/Ethnicity. Pediatrics, 123, 697-702. http://dx.doi.org/10.1542/peds.2008-0687 
[8] Black, J. and Hawks, J., Eds. (2005) Medical-Surgical Nursing: Management for Positive Outcomes. 8th Edition, Saunders, New York.

[9] Palmeira, A., Branco, T., Martins, S., Minderico, C., Silva, M., Vieira, P., Barata, J., Serpa, S., Sardinha, L. and Teixeira, P. (2010) Change in Body Image and Psychological Well-Being during Behavioral Obesity Treatment: Associations with Weight Loss and Maintenance. Body Image, 7, 187-193. http://dx.doi.org/10.1016/j.bodyim.2010.03.002

[10] Kokonyei, G., Baldacchino, A., Urbán, R. and Demetrovics, Z. (2013) The Psychological Basis of Obesity. Obesity, 7, 39-51. http://dx.doi.org/10.1016/b978-0-12-416045-3.00004-2

[11] Mommersteeg, P.M.C., Herr, R., Bosch, J., Fischer, J.E. and Loerbroks, A. (2011) Type D Personality and Metabolic Syndrome in a 7-Year Prospective Occupational Cohort. Journal of Psychosomatic Research, 71, 357-363. http://dx.doi.org/10.1016/j.jpsychores.2011.05.004

[12] Crosnoe, R. (2012) Obesity, Family Instability, and Socioemotional Health in Adolescence. Economics \& Human Biology, 10, 375-384. http://dx.doi.org/10.1016/j.ehb.2012.04.005

[13] Olson, D.H. (1999) Circumplex Model of Marital and Family Systems. Journal of Family Therapy, 22, 144-167. http://dx.doi.org/10.1111/1467-6427.00144

[14] Lingren, M.G. (2003) Creating Sustainable Families (On-Line). http://digitalcommons.unl.edu/extensionhist/551/

[15] Zimmer-Gembeck, M.J. and Lockes, E.M. (2007) The Socialization of Adolescent Coping Behaviours: Relationship with Families and Teachers. Journal of Adolescence, 30, 8-16. http://dx.doi.org/10.1016/j.adolescence.2005.03.001

[16] Damas, E.J. and Laughlin, J. (2001) Latent Model of Family Process in African American Families; Relationships to Child Competence, Achievement, and Problem Behavior. Journal of Marriage and Family, 63, 967-980. http://dx.doi.org/10.1111/j.1741-3737.2001.00967.x

[17] Victor, M., Bernat, H. and Bernstien, L. (2007) Effect of Parent and Family Characteristics on Treatment Outcome of Anxious Children. Journal of Anxiety Disorder, 21, 835-898. http://dx.doi.org/10.1016/j.janxdis.2006.11.005

[18] Grilo, C.M., Masheb, R.M. and Wilson, T.G. (2006) Rapid Response to Treatment for Being Eating Disorder. Journal of Counseling of Clinical Psychology, 74, 602-613. http://dx.doi.org/10.1037/0022-006X.74.3.602

[19] Billings, A.G. and Moos, R.H. (2008) The Role of Coping Responses and Social Resources in Attenuating the Stress of Life Events. Journal of Behavioral Medication, 4, 139-157. http://dx.doi.org/10.1007/BF00844267

[20] Mack, D., Strong, H., Kowalski, K. and Crocker, P. (2007) Self-Presentational Motives in Eating Disordered Behavior: A Known Group’s Differences Approach. Eating Behaviours, 8, 98-105. http://dx.doi.org/10.1016/j.eatbeh.2006.02.004

[21] Hong, R.Y. (2007) Worry and Rumination: Differential Associations with Anxious and Depressive Symptoms and Coping Behavior. Journal of Behavioral Research and Therapy, 45, 277-290. http://dx.doi.org/10.1016/j.brat.2006.03.006

[22] McLaughlin, K.A., Mennin, D.S. and Farach, F.J. (2006) The Contributory Role of Worry in Emotion Generation and Dysregulation in Generalized Anxiety Disorder. Behavior Therapy, 45, 1735-1752. http://dx.doi.org/10.1016/j.brat.2006.12.004

[23] Oathes, D.J. (2008) Worry, Generalized Anxiety Disorder, and Emotion: Evidence from the EEG Gamma Band. Journal of Biological Psychology, 79, 1650-1670. http://dx.doi.org/10.1016/j.biopsycho.2008.04.005

[24] Brosschota, J.F., Gerinb, W. and Thayer, J.F. (2006) The Perseverative Cognition Hypothesis: A Review of Worry, Prolonged Stress-Related Physiological Activation, and Health. Journal of Psychosomatic Research, 60, 113-124. http://dx.doi.org/10.1016/j.jpsychores.2005.06.074

[25] Knepp, M.M. and Friedman, B.H. (2008) Cardiovascular Activity during Laboratory Tasks in Women with High and Low Worry. Journal of Biological Psychology, 79, 287-293. http://dx.doi.org/10.1016/j.biopsycho.2008.07.002

[26] Kinzl, J.F., Traweger, C., Trefal, T.E., Riccabona, U. and Ledere, R.W. (2007) Work Stress and Gender-Dependent Coping Strategies in Anesthesiologists at a University Hospital. Journal of Clinical Anesthesia, 19, 334-338. http://dx.doi.org/10.1016/j.jclinane.2006.08.014

[27] Bergman, B., Ahmad, F. and Stewart, D.E. (2003) Physician Health, Stress and Gender at a University Hospital. Journal of Psychosomatic Research, 54, 171-178. http://dx.doi.org/10.1016/S0022-3999(02)00484-1

[28] Sotodeh, A. (2000) The Examination of Validity and Reliability of Job Stress Questionnaire in Clerks of Esfahan City. Master's Thesis, Shiraz University, Shiraz. (In Persian)

[29] Rahimian Boogar, E., Nouri, A., Oreizy, H., Molavi, H. and Foroughi Mobarake, A. (2007) Relationship between Adult Attachments Styles with Job Satisfaction and Job Stress in Nurses. Iranian Journal of Psychiatry and Clinical Psychology, 13, 148-157. (In Persian)

[30] Colangelo, N. and Davis, G., Eds. (2003) Handbook of Gifted Education. Allyn \& Bacon, Boston. 
[31] Cocker, S. and Roger, D. (1990) The Construction and Preliminary Validation of a Scale for Measuring Eating Disorders. Journal of Psychosomatic Research, 34, 223-231. http://dx.doi.org/10.1016/0022-3999(90)90056-A

[32] Shakeri, S.H. (2003) Effects of Family Flexibility on Mental Health of Middle School Students in Shiraz. Master's Thesis, Shiraz University, Shiraz. (In Persian)

[33] Marina, G.N. and Raphael D.R.L. (2011) Binge Eating Disorder and Body Image Perception among University Students. Eating Behaviors, 12, 284-288. http://dx.doi.org/10.1016/j.eatbeh.2011.07.004

[34] Grosec, J.R. (2001) Correlates of Authoritarian Parenting in Individualist and Collectivistic Cultures and Implications for Understanding the Transmission of Values. Journal of Cross-Cultural Psychology, 32, 202-212. http://dx.doi.org/10.1177/0022022101032002007

[35] Terry, D. (2008) Determinants of Coping the Role of Stable and Situational Factor. Journal of Personality and Social Psychology, 66, 895-910.

[36] Terman, L.M. (1925) Mental and Physical Traits of a Thousand Gifted Children. Genetic Studies of Genius. Volume 1, Stanford University Press, Stanford.

[37] Henderson, H. and Freeman, C.P.L. (1987) A Self-Rating Scale for Bulimia. The BITE. British Journal of Psychiatry, 150, 18-24. http://dx.doi.org/10.1192/bjp.150.1.18

[38] Lot, S., Helen, S., Saeidi, S., Morgan, J., Hugo, P., Russell, A. and Schmidt, A. (2012) Understanding Catastrophic Worry in Eating Disorders: Process and Content Characteristics. Journal of Behavior Therapy and Experimental Psychiatry, 43, 1095-1103. http://dx.doi.org/10.1016/j.jbtep.2012.05.006

[39] Fiese, A.H. and Diana, G.T. (2012) Family Mealtimes: A Contextual Approach to Understanding Childhood Obesity. Economics and Human Biology, 19, 365-374. http://dx.doi.org/10.1016/j.ehb.2012.04.004

[40] Michele, P. and Marilyn, F. (2012) Parenting Behaviors of African American and Caucasian Families: Parent and Child Perceptions, Associations with Child Weight, and Ability to Identify Abnormal Weight Status. Journal of Pediatric Nursing, 27, 195-205. http://dx.doi.org/10.1016/j.pedn.2011.03.012

[41] Hutchinson, D.M. and Rapee, R.M. (2007) Do Friends Share Similar Body Image and Eating Problems? The Role of Social Networks and Peer Influences in Early Adolescence. Behavioral Research Therapy, 45, 1557-1577. http://dx.doi.org/10.1016/j.brat.2006.11.007

[42] Berk, L.E. (2013) Development through the Lifespan. 6th Edition, Pearson, Boston.

[43] Jamshidi, B., Razmia, M., Haghighatb, S. and Samani, S. (2008) The Relationship between Family Cohesion and Flexibility with Dimensions of Perfectionism. Iranian Journal of Psychiatry and Clinical Psychology, 14, 199-205. (In Persian) 